\title{
Malignant pheochromocytoma - a challenging diagnosis
}

Liliana Topor ${ }^{11}$, Anca Sîrbu ${ }^{1,2}$

1. Elias University Hospital, Endocrinology, Diabetes and Nutrition Diseases Department, Bucharest, Romania

2. Carol Davila University of Medicine and Pharmacy, Endocrinology Department, Bucharest, Romania

\section{Introduction:}

Pheochromocytoma is a rare tumor arising from chromaffin cells located originally in the adrenal medulla. Malignant pheocromocytoma is an even more rare tumor, being accepted that about $10 \%$ of pheochromocytoma is malignant, and it is a difficult disease because it is diagnosed only in the presence of metastases, with no definitive histological or cytological criteria of malignancy. It typically metastasizes to local lymph nodes, bone (50\%), liver (50\%) and lung (30\%) (1); the metastasis being defined as the presence of chromaffin tissue in nonchromaffin organs.

Case report:

History: A 38 years old woman, without pathological personal history, presented for hypertension (maximum of the systolic blood pressure $=160 \mathrm{mmHg}$ ), palpitation and dyspnea. From her family antecedents it should be remembered: mammary cancer at a second degree relative and hypertension at a first degree relative.

Clinical examination: palpable adenophaties at the submandibular level, bilateral laterocervical and in the left axilla, with maximum diameter of $1 \mathrm{~cm}$, mobile on all plans; blood pressure equal at both arms $=110 / 60 \mathrm{mmHg}$ without orthostasis, heart rate $70 / \mathrm{min}$, with no other pathological modifications.

Laboratory test:

- Biological tests were normal;

- Hormonal profile - the only modifications were metanephrine raised 5.4 fold (486.8 $\mathrm{pg} / \mathrm{ml})$ and normetanephrine raised 1.35 fold $(244.6 \mathrm{pg} / \mathrm{ml})$, the other hormona measurements being in normal limits: $\mathrm{TSH}=1,36 \mu \mathrm{UI} / \mathrm{ml}$, $\mathrm{iPTH}=58,52 \mathrm{pg} / \mathrm{ml}$, $\mathrm{ACTH}=10,1 \mathrm{pg} / \mathrm{ml}$, cortisol=18,3 $\mu \mathrm{g} / \mathrm{ml}(8 \mathrm{a} . \mathrm{m}$.), with normal nycthemeral rhythm, prolactin $=19,46 \mathrm{ng} / \mathrm{ml}$, FSH $8,93 \mathrm{mUi} / \mathrm{ml}, \mathrm{LH}=6,8 \mathrm{mUi} / \mathrm{ml}$, estradiol=52,54 $\mathrm{pg} / \mathrm{ml}$ (the 3 th day of menstrual cycle), testosterone $=23,6 \mathrm{ng} / \mathrm{ml}$.
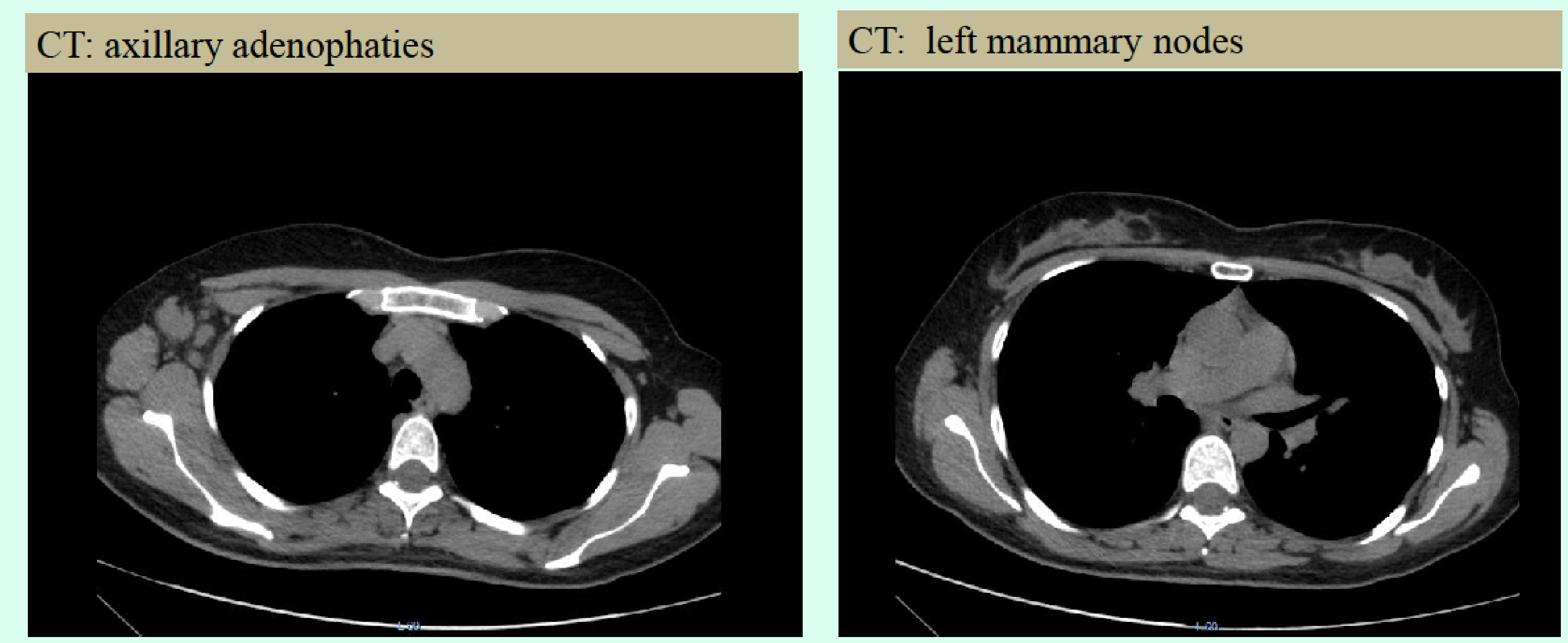
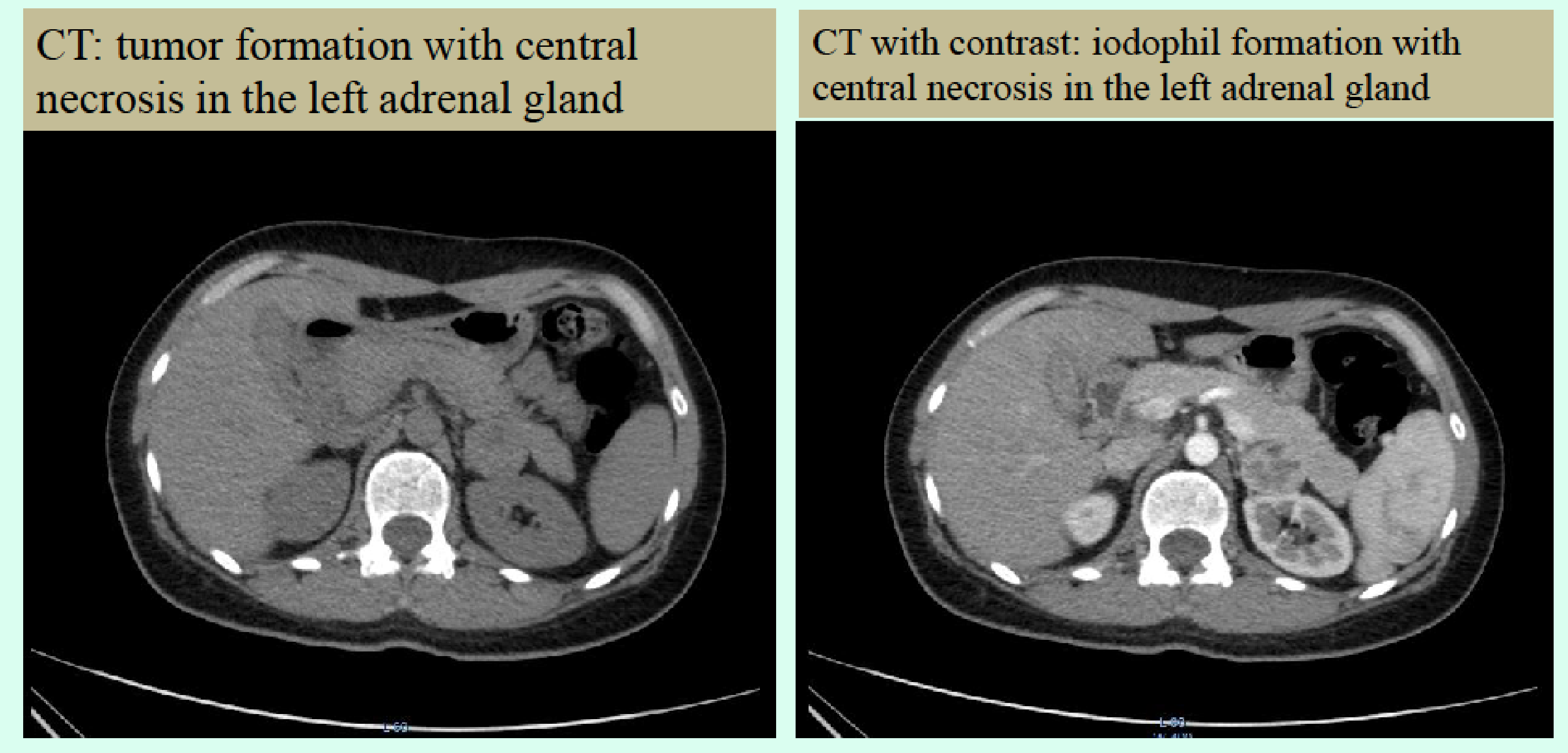

Imaging exams:

- Ultrasonography - normal thyroid gland, laterocervical and submandibular adenophaties and a node in left breast;

- Thoraco-abdomino-pelvic contrast CT: an iodophil formation of $29 / 26 \mathrm{~mm}$, with central necrosis in the left adrenal, two pulmonary micronodules, bilateral multiple axillary adenophaties predominantly at the right axilla with maximum diameter $24 \mathrm{~mm}$, left mammary nodes $24 / 16 \mathrm{~mm}$, two hypodense and iodophyl formations in the liver space of 24 $\mathrm{mm}$ and $38 \mathrm{~mm}$; multiple abdomino-pelvic adenophaties with maximum diameter $-14 \mathrm{~mm}$

- Cerebral CT: no lesions or formations observed.
Evolution:

It was preceded left unilateral adrenalectomy and the histophatologic exam confirm the diagnosis of pheochromocytoma (tumor size $3 \mathrm{~cm}$ ). Furthermore, two weeks postsurgery the metanephrine and normetanephrine are maintained elevated (metanephrine raised about 5 times and normetanephrine about 2 times).

\section{Discussion:}

Malignant pheochromocytoma is a controversial diagnosis starting from its definition, malignancy being determined only in the presence of metastasis with no other criteria. In the literature are several markers suggested to correlate with the risk of malignancy like : tumor weight $>80 \mathrm{~g}$ and high, tumor concentration of dopamine (2), tumor size $>5 \mathrm{~cm} \mathrm{(3),} \mathrm{the} \mathrm{presence} \mathrm{of}$ confluent tumor necrosis, extra-adrenal manifestations and a younger age (4). Also, several scoring system to predict the malignancy has been proposed like

- The Pheochromocytomas of the Adrenal Gland Scaled Score (PASS) which has included invasion, histologic growth patterns, cytological features, mitotic activity, and other characteristics (5), but currently is no consensus on adoption of a formal scoring system. There are more other markers: biochemical markers(e.g. methoxytyramine, chromogranin A, neuron-specific enolase), imaging markers (e.g.123Imetaiodobenzylguanidine scintigraphy (123I-MIBG), PET with 6-[18F]-fluoroDOPA ([18F]-DOPA), 111Inpentetreotide), histologic markers (e.g. Ki-67 proliferative index, hTERT mRNA, the heat shock protein HSP 90, vascular endothelial growth factor) studied in relationship with cromaffin tumors but with no conclusive data. Even if some of them appears to diagnose better the presence of metastases like 123I-MIBG, [18F]-DOPA their availability is not that accessible.
CT with contrast: iodophyl formation in the liver space - eight segment

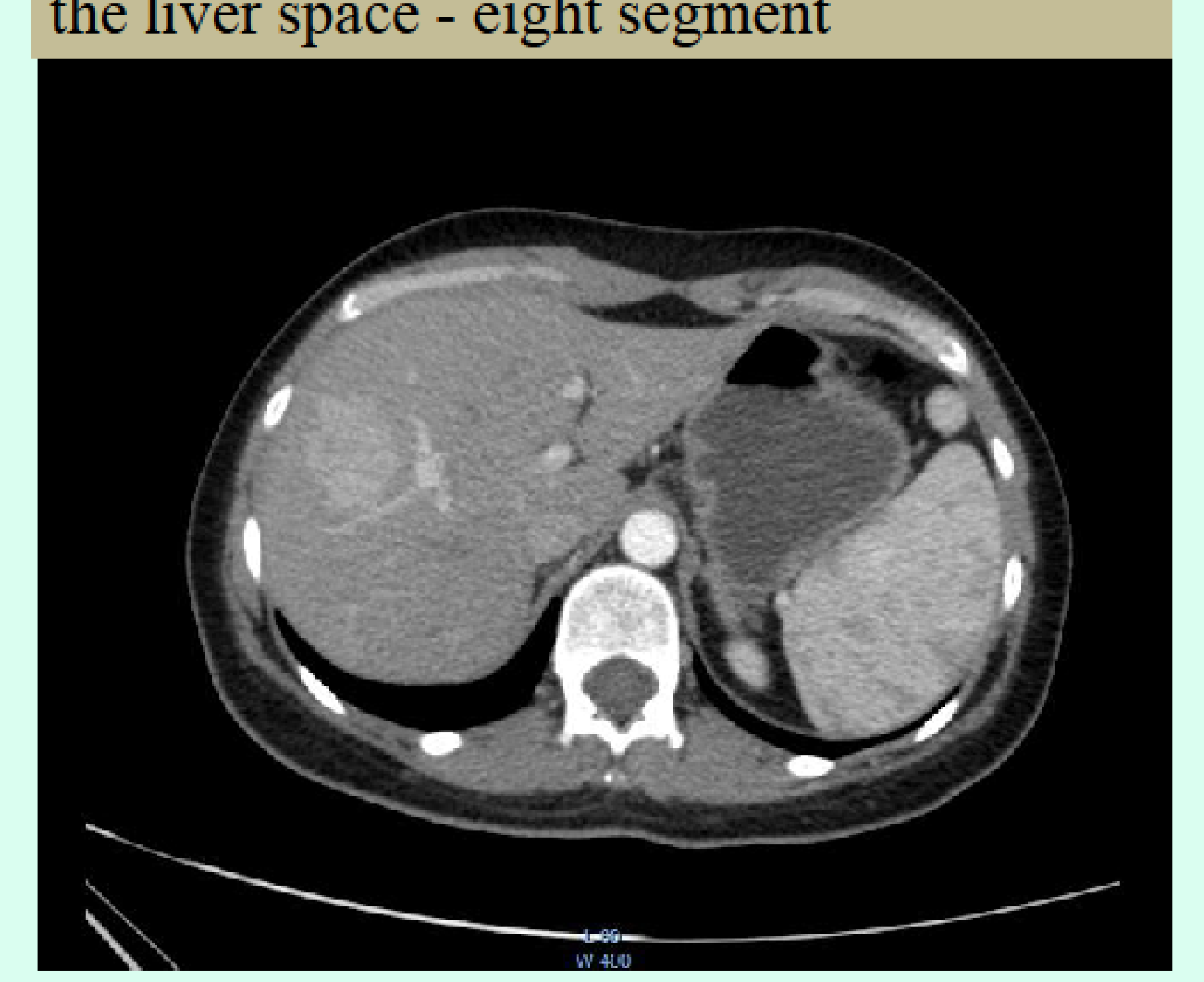

CT with contrast: iodophyl formation in the liver space - second segment

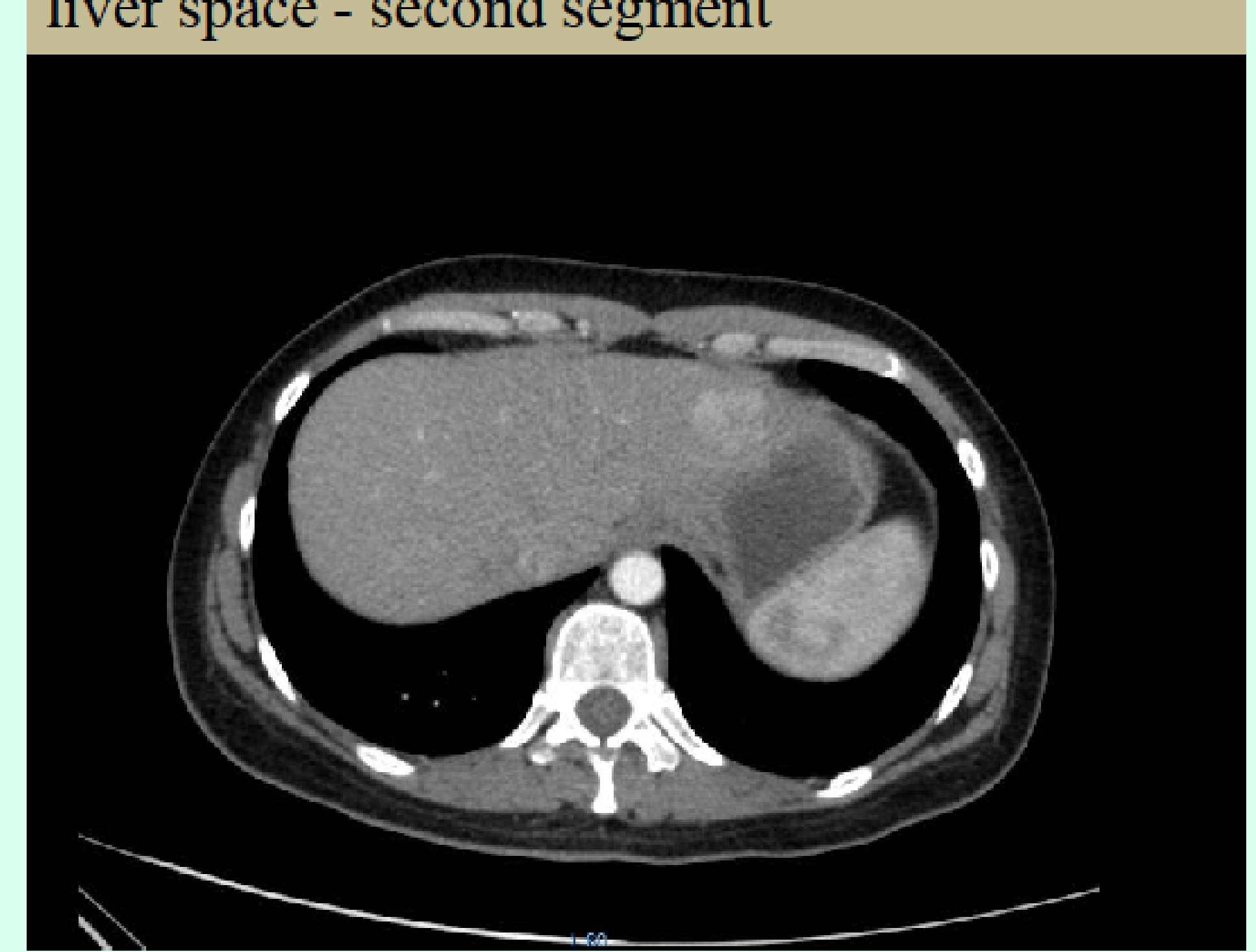

\section{Conclusions}

We present a case of a young woman with catecholamine hypersecretion and a mass in the left adrenal - a pheochromocytoma, with associated lymphadenopathies, liver formations and pulmonary micronodules- places where pheochromocytoma usually metastasizes, and with metanephrine and normetanephrine maintained elevated postsurgery, so most probably malignant pheochromocytoma. The final diagnosis could be established only after the demonstration of chromaffin cells in the nonchromaffin tissues. Although the clinical presentation and the laboratory findings were not that impressive, the malignant pheochromocytoma cannot be excluded regarding its definition, so other noninvasive, sensitive, specific and accessible criteria of diagnosis would be necessary. 